\title{
Demography and Mortality of Body Packers; an Extended Experience from a Referral Center
}

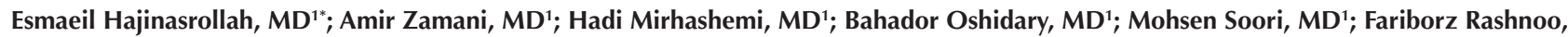 \\ MD'; Hassan Peyvandi, MD'; Mohammad Amin Shahrbaf, MD²
}

'Departemnt of General Surgery Loghman Medical Center, Shahid Beheshti University of Medical Sciences, Tehran, Iran

${ }^{2}$ School of Medicine, Faculty of Medicine, Shahid Beheshti University of Medical Sciences, Tehran, Iran

\begin{abstract}
Background: The incidence of smuggling and illegal transport of substances by internal concealment, also known as body packing, is increasing. The clinical approach to body packers has changed significantly over the past two decades. In addition, the mortality of body packers is an important issue in patient management. The purpose of the current study is to determine the statistics and mortality related to body packing.

Methods: In this cross-sectional study, all body packer patients who referred to Loghman Hakim hospital were evaluated from 2010 to 2017. Demographic characteristics, findings of clinical imaging, treatment, and outcome of the patients were recorded. The data were analyzed using SPSS version 21.

Results: A total of 303 patients were enrolled in the study after the diagnosis of body packing by abdominal CT scanning without contrast. Conservative treatment including whole bowel irrigation ( $\mathrm{WBI}$ ) accompanied by close monitoring was done for $78 \%$ $(\mathrm{n}=236)$ of patients; moreover, 26 patients $(8.5 \%)$ underwent surgery after $\mathrm{WBI}$, and 41 patients $(13.5 \%)$ underwent surgery without bowel irrigation. Mortality was observed in eight patients $(2.7 \%)$ five of whom $(62.5 \%)$ died before surgery and had the clinical manifestation of crystal (methamphetamine) and cannabis toxicity. Furthermore, three patients (37.5\%) died due to the complications of surgery such as gastrointestinal leakage of an abdominal abscess.

Conclusion: Conservative treatment seems to be better for the management of body packers. In addition, it is necessary to monitor patients for possible signs and symptoms of intoxication and gastrointestinal obstruction.

Keywords: Body packing, Body stuffing, Drug concealment, Drug smuggling, Illicit substance

Cite this article as: Hajinasrollah E, Zamani A, Mirhashemi H, Oshidary B, Soori M, Rashnoo F, et al. Demography and mortality of body packers; an extended experience from a referral center. Arch Iran Med. 2020;23(8):542-547. doi: 10.34172/aim.2020.57.
\end{abstract}

Received: October 24, 2019, Accepted: June 2, 2020, ePublished: August 1, 2020

\section{Introduction}

Body packers are people who transport illegal substances within their bodies in order to circumvent tracking by the police. ${ }^{1-3}$ Body packers usually hold a large amount of drugs which are inserted in different parts of the body such as oral cavity, rectum, and vagina. ${ }^{4,5}$ Body stuffers or mini body packers are people who carry minor quantities of materials to avoid detection and carry the substances for immediate resale or individual use. ${ }^{6}$ Cocaine, heroin and cannabis derivatives such as hashish, crystal and grass are materials carried by body packers. ${ }^{7,8}$ The amount of drug in body packers is approximately 1 kilogram and it is usually divided into multiple packets which can be made from different materials such as latex and aluminum foils but condoms are the most common type of packets. ${ }^{9-11}$

Body packing may have serious medical complications including drug intoxication, which can be fatal, intestinal or pyloric obstruction caused by packets and, rarely rupture of packets. ${ }^{12-14}$ Management of body packers is different based on the type of drugs. ${ }^{15}$ In addition, the mortality of body packers is related to some factors including early diagnosis and general condition of patients which is related to the patients' approach. ${ }^{16}$

This study aimed to describe the demographic characteristics, complications and mortality rate of body packers and body stuffers who were referred to Loghman Hakim hospital, the referral center for body packers in Iran.

\section{Patients and Methods \\ Study Design}

This cross-sectional study was done on body packers who were referred to the poising department of Loghman Hakim medical center from 2010 to 2017 . In this regard, all body packers who were arrested by the police and referred to our medical center were enrolled in the current study. The inclusion criterion was the presence of illicit substance in the body of the patient diagnosed by imaging. The exclusion criteria included presence of missing data in the management details of the patients' record. The standard diagnostic procedure for the patients consisted of abdominal CT scan without contrast and abdominal 
$\mathrm{X}$-ray. ${ }^{17}$ Some of the diagnostic features of abdominal X-ray and CT scan are presented in Figures 1 and 2.

Patient Management

After admitting the body packers, a standard algorithm which includes non-surgical and surgical procedures was used for patient management (Figure 3). ${ }^{18-20}$ All of the patients were initially resuscitated in the emergency department. After that, all of the intoxicated patients were managed conservatively with activated charcoal (0.5-1 $\mathrm{g} / 250 \mathrm{~mL}$ water) and whole bowel irrigation (WBI) with polyethylene glycol 7\%. In addition, anti-dote was used for intoxicated patients. Surgery was used for patients with gastrointestinal obstruction and peritonitis; furthermore, unstable intoxicated patients who did not respond to antidote were managed surgically. Body packers were observed in the poisoning department until complete evacuation of packets, or until the passage of at least three stools free from drug packages. Moreover, a second CT scan was performed prior to medical discharge.

The patients' records were thoroughly reviewed for the demographic data and management details. Demographic data included age, sex, carrier and carrying type, characteristics of the drugs, the time between ingestion and admission, and symptoms and signs at the time of admission. Management details included type of management (conservative or surgical), the indications and methods of the surgical management, the hospitalization time after surgery and the final outcome of the patients. All data were extracted from the patients' files into a

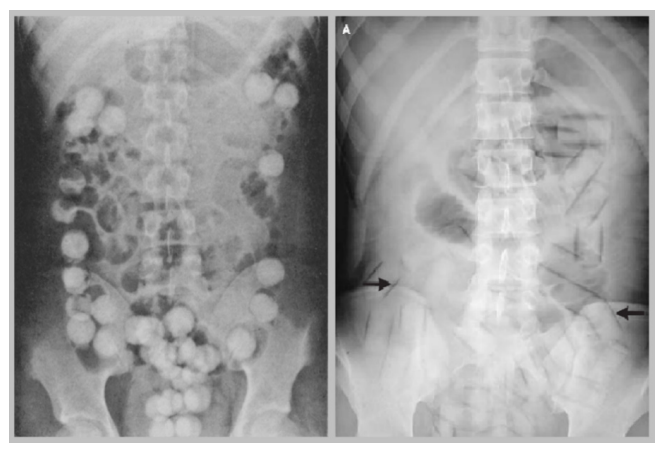

Figure 1. Abdominal X-ray of a Body Packer. Multiple tubular foreign bodies are observed in the abdomen. Some of the pockets have air in cover (arrow).

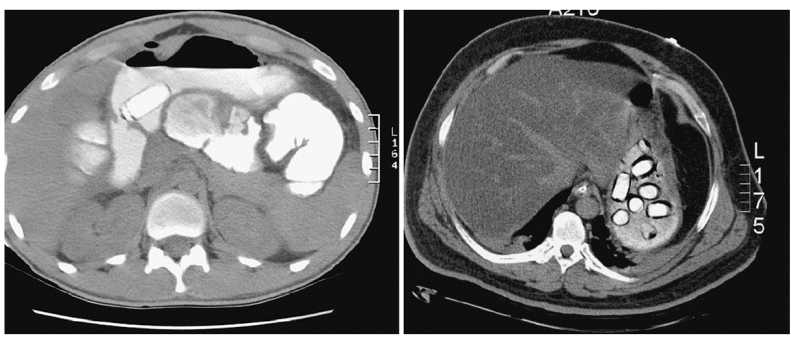

Figure 2. CT Scan of the Abdomen. Multiple tubular packs are seen in the stomach and colon. separate sheet designed for each patient. Another reviewer checked the accuracy of data entry into the patients' sheet in a random sample of the patients (80 patients).

\section{Statistical Analysis}

Statistical analysis was done using version 21 of SPSS software with a special focus on the description of the patients. Qualitative variables were expressed as percent (\%); in addition, quantitative variables were shown as mean \pm standard deviation (SD).

\section{Results}

In this study, 319 patients were initially included, and 303 patients were evaluated in the final analysis. In total, 16 patients were excluded because of missing data in management details. Among 303 body packers, 289 patients $(95.4 \%)$ were male and 14 (4.6\%) were female. The mean age of the body packers was $33.46 \pm 9.22$ years with a range of 17 to 62 years. One hundred seventy-four patients $(57 \%)$ had a history of addiction.

In terms of the carrier type, $103(34 \%)$ were classified as body packers; furthermore, 156 (51.5\%) and 44 (14.5\%) were classified as body stuffers and indeterminate/mixed

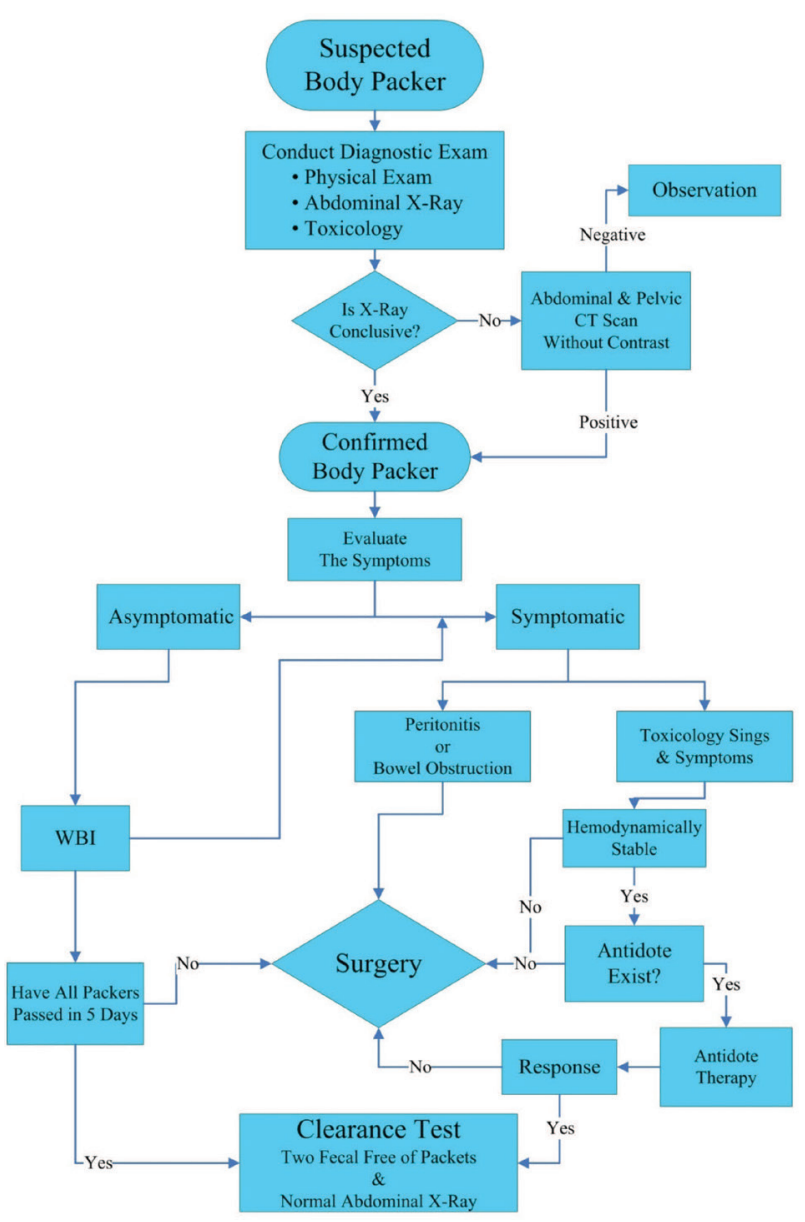

Figure 3. Suggested Algorithm for Management of Body Packers and Body Stuffers. The figure is reproduced with permission from the study by Alipour-faz et al. ${ }^{19}$ 
carrier respectively. Moreover, 98.02\% of patients ( $\mathrm{n}=$ 297) chose ingestion as the carrying method and 6 patients $(1.98 \%)$ were vaginal and rectal pushers. The median time for arriving at the hospital after ingestion was 42 hours (mean \pm SD was: $20.14 \pm 33.63$ ).

The most common drugs were crack in 120 patients (39.6\%), crystal in 47 patients (15.5\%), opium in 36 patients $(11.9 \%)$ and heroin in 22 patients (7.2\%). Moreover, 78 patients $(25.8 \%)$ carried unknown drugs (the patients did not mention the type of the drugs). The mean number of the ingested packs was 10.34 \pm 23.4 (median number: 30) ranging from 1 to 150 ; Furthermore, the mean weight of packages was $71.81 \pm$ $258.3 \mathrm{~g}$ (median weight: 242) ranging from $5 \mathrm{~g}$ to $2000 \mathrm{~g}$. The demographic data are presented in Table 1.

In terms of patient management, conservative treatment was used for 220 patients $(72.6 \%)$, while WBI with surgery was done on 32 patients (10.6\%). In addition, 51 patients $(16.8 \%)$ were managed only by surgery. The indications for surgery were clinical manifestations of toxicity in $50(60.25 \%)$ patients and GI obstruction (Figure 4), peritonitis and GI bleeding in 33 (39.75\%) patients.

The surgical site of packs was stomach in $33.7 \%$ $(\mathrm{n}=28)$, small intestine in $39.7 \%(\mathrm{n}=33)$ and, colosigmoidorectal in $20.6 \%(\mathrm{n}=17)$ patients. Furthermore, no packs were excreted in 5 patients $(6 \%)$. The most common surgical techniques were laparotomy and gastrotomy $(21.7 \%, \mathrm{n}=18)$; other surgical techniques included rectosigmoidoscopy, laparotomy and gastrotomy and milking till and, laparotomy and gastrotomy and enterotomy.

The mean duration of hospitalization was $3.8 \pm 4$ days

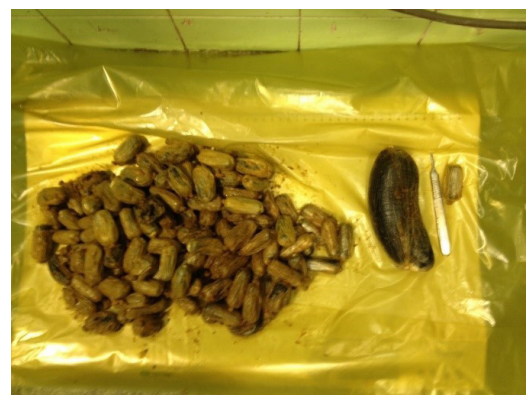

Figure 4. A Rectal Pusher Who Presented with Intestinal Obstruction.

with conservative management and $5.6 \pm 4$ days with surgical treatment. Mortality rate was $2.7 \%(n=8)$. Five of eight patients $(62.5 \%)$ who had clinical manifestations of toxicity with crystal (methamphetamine) died before surgery and were unsuccessfully resuscitated at the presentation in the emergency department. Three patients (37.5\%) died due to the complications of surgery like GI leakage and abdominal abscess (Table 2).

\section{Discussion}

In the present study, most patients were young males and approximately $50 \%$ of them were addicts; moreover, most of them were body stuffers who carried a small quantity of an illicit substance. In our settings, the diagnostic procedure for detecting internal concealment of drugs was CT scan, as a result of the low sensitivity of $\mathrm{x}$-ray to reveal the presence of small packages of drugs in the body stuffers. ${ }^{21-23}$ The most common treatment approach was conservative management of a patient which is in line with the recent studies. ${ }^{24-26}$

Drug smuggling by body packers and body stuffers is a

Table 1. Demographic Characteristics of Body Packers

\begin{tabular}{|c|c|c|c|}
\hline Variables & & Results & Valid Cases (\%) \\
\hline Age (year) & & $33.46 \pm 9.22$ (Range: $17-62)$ & $303(100 \%)$ \\
\hline \multirow{2}{*}{ Gender } & Male & $289(95.4 \%)$ & \multirow{2}{*}{$303(100 \%)$} \\
\hline & Female & $14(4.6 \%)$ & \\
\hline \multirow{3}{*}{ Carrier type } & Body packing & $103(34 \%)$ & \multirow{3}{*}{$303(100 \%)$} \\
\hline & Body stuffing & $156(51.5 \%)$ & \\
\hline & Indeterminate/mixed & $44(14.5 \%)$ & \\
\hline \multirow{2}{*}{ Carrying type } & Ingestion & $297(98.02 \%)$ & \multirow{2}{*}{$303(100 \%)$} \\
\hline & Rectal/vaginal pusher & $6(1.98 \%)$ & \\
\hline Time of arrival (h) & & $20.14 \pm 33.63$ (Median: 42, Range: 0.5-264) & $276(91.1 \%)$ \\
\hline Number of packs & & $10.34 \pm 23.4$ (Median: 30, Range: $1-150$ ) & $298(98.3 \%)$ \\
\hline Weight of packs (g) & & $71.81 \pm 258.3$ (Median: 242, Range: $5-2000$ ) & $298(98.3 \%)$ \\
\hline Addiction history & & $174(57.4 \%)$ & $281(92.7 \%)$ \\
\hline \multirow{3}{*}{ Signs and symptoms } & Normal & $227(75 \%)$ & \multirow{3}{*}{$303(100 \%)$} \\
\hline & Intoxicated & $73(24 \%)$ & \\
\hline & Need surgical management & $3(1 \%)$ & \\
\hline \multirow{5}{*}{ Type of drug } & Crack & $112(37 \%)$ & \multirow{5}{*}{$221(72.9 \%)$} \\
\hline & Crystal & $51(16.8 \%)$ & \\
\hline & Opium & $40(13.2 \%)$ & \\
\hline & Heroin & $18(6 \%)$ & \\
\hline & Unknown & $82(27 \%)$ & \\
\hline
\end{tabular}


Table 2. Management Details of Body Packers

\begin{tabular}{|c|c|c|c|}
\hline Variables & & Results & $95 \% \mathrm{Cl}$ \\
\hline \multirow{3}{*}{ Type of management } & Only surgery & $51(16.8 \%)$ & $12.9 \%-21.3 \%$ \\
\hline & WBI + surgery & $32(10.6 \%)$ & $7.5 \%-14.4 \%$ \\
\hline & Conservative & $220(72.6 \%)$ & $67.4 \%-77.4 \%$ \\
\hline \multirow{2}{*}{ Surgery indication } & Clinical manifestation of toxicity & $50(60.25 \%)$ & $49.5 \%-70.3 \%$ \\
\hline & Obstruction, peritonitis and, GIB & $33(39.75 \%)$ & $29.7 \%-50.5 \%$ \\
\hline \multirow{4}{*}{ Surgical technique } & Laparotomy and gastrotomy & $18(21.7 \%)$ & $13.9 \%-31.4 \%$ \\
\hline & Rectosigmoidoscopy & $7(8.4 \%)$ & $3.9 \%-15.8 \%$ \\
\hline & Laparotomy and gastrotomy and milking & $54(65 \%)$ & $54.4 \%-74.7 \%$ \\
\hline & Laparotomy and gastrotomy and enterotomy & $4(4.9 \%)$ & $1.6 \%-11.1 \%$ \\
\hline \multirow{4}{*}{ Surgical site of packets } & Stomach & $28(33.7 \%)$ & $24.6 \%-44.8 \%$ \\
\hline & Small intestine & $33(39.7 \%)$ & $30.1 \%-51 \%$ \\
\hline & Colosigmoidorectal & $17(20.6 \%)$ & $13.1 \%-30.4 \%$ \\
\hline & No pack & $5(6 \%)$ & $1.7 \% \quad 11.2 \%$ \\
\hline \multirow{2}{*}{ Hospitalization (day) } & Conservative Group & $3.8 \pm 4$ & $3.74-3.99$ \\
\hline & Surgical Management Group & $5.6 \pm 4$ & $5.63-6.19$ \\
\hline \multirow{2}{*}{ Final outcome } & Recovery & $295(97.3 \%)$ & $95.1 \%-98.7 \%$ \\
\hline & Death & $8(2.7 \%)$ & $1.3 \% \quad 4.9 \%$ \\
\hline
\end{tabular}

WBI, whole bowel irrigation; GIB, gastrointestinal bleeding.

serious and growing problem. Since the first reports in the $1970 s,{ }^{27}$ there has been a significant decrease in morbidity and mortality of these patients. ${ }^{28}$ Furthermore, the rate of body packing is decreasing after the use of $x$-ray in airports. ${ }^{29}$

This study can be considered as an extension to AlipourFaz and colleagues' study which was also conducted in our center. ${ }^{19}$ In the present study, we doubled the number of patients and we updated the follow-up of the previously reviewed patients in term of their long-term follow-up and complications. The mortality remained $2.7 \%$ which is in line with the initial results of Alipour-faz and colleagues' study which reported $3 \%$ mortality rate. ${ }^{19}$ In addition, the mean length of hospitalization in our study was 5.6 and 3.8 days for the surgical management and conservative groups, respectively, which is in line with the findings reported by Beckley et al. ${ }^{28}$

As mentioned previously, ${ }^{19}$ crack was the most common illicit drug transported by the packers, which is in contrast to the previous study. In a study by Hassanian-Moghadam et al, opium was the most common illicit drug in Iran. ${ }^{30}$ Flach et al reported that cocaine and heroin are the most common drugs in body packers. ${ }^{23}$ Furthermore, in studies by Heymann et al, Alfa-Wali et al and Markovits et al, cocaine was the major illicit substance. ${ }^{31-33}$ This difference may be due to the limited availability and high price of cocaine and heroin in Iran. In this study, the most common site of drug concealment was the stomach. This result is similar to previous studies. ${ }^{19,34}$

Body packers present to hospitals because they have been arrested or developed complications, such as drug intoxication or intestinal obstruction. ${ }^{35}$ In the current study, $24 \%$ of body packers presented voluntarily to the emergency department due to intoxication symptoms; in addition, $1 \%$ of patients need surgical treatment due to complications. The risk of packets perforation is rising due to the increase in the number of packets ingested. ${ }^{36}$ However, improvement in the quality of drug packaging has a significant effect on the success of conservative treatment. ${ }^{37}$

Need for surgical intervention was $27.4 \%$ in our study which is in contrast with a study by Veyrie et al which reported a $3 \%$ need for surgical intervention. ${ }^{38}$ More than two thirds of surgical cases underwent only surgical management and the others underwent WBI with surgery. It is better to use a surgical approach for the intoxicated and complicated cases or if the nature of the illicit substance is unknown. ${ }^{39}$ The preferred surgical technique for body packers is laparotomy with gastrotomy and milking ${ }^{19}$; we use this method for $65 \%$ of surgical management cases. This method is effective in removing the drug pockets successfully. ${ }^{3}$ However, multiple enterotomies are preferable when the drug is widely spread in the GI tract. ${ }^{40,41}$

This study is limited by the presence of missing data in patients' records including the future follow-up of the patients who underwent conservative management. Most of these patients are lost to follow-up because of their socioeconomic status and the nature of their condition which is considered a crime. However, all of the patients were discharged in stable conditions.

In conclusion, body packers with proven drug packets in

\section{Key Points}

- That body packers with proven drug packets in the GI tract can be treated conservatively.

- Surgical management should be performed in body packers with signs of intoxication or obstruction.

- Careful monitoring of patients is necessary for choosing the best management and reducing the rate of mortality. 
the GI tract can be treated conservatively. We recommend surgery to be performed only for body packers with signs of intoxication or obstruction and to subject all other patients to conservative treatment. In addition, careful monitoring of patients is necessary for choosing the best management and reducing the rate of mortality.

\section{Authors' Contribution}

AZ gathered the data, analyzed the data, wrote the draft of the manuscript, finally revised the manuscript. MAS gathered the data, analyzed the data, helped in drafting, approved the final manuscript. $\mathrm{EH}$ had the idea, supervised the data gathering and drafted the article, confirmed the final manuscript. HM, BO, MS, FR and HP, supervised the data gathering and analysis, revised the manuscript, approved the final manuscript.

\section{Conflict of Interest Disclosures}

The authors declare that they have no conflict of interest.

\section{Ethical Statement}

The study was approved by the Ethics Committee of Loghman Hakim hospital and Shahid Beheshti University of medical sciences, Tehran, Iran

\section{Informed Consen}

We did not provide individual informed consents signed by all patients due to cross-sectional nature of the study. However, the patients were informed about the potential use of their information in the future study when admitted.

\section{Funding}

None of the authors received any funding.

\section{References}

1. Traub SJ, Hoffman RS, Nelson LS. Body packing--the internal concealment of illicit drugs. N Engl J Med. 2003;349:251926. doi: 10.1056/NEJMra022719.

2. Booker R, Smith J, Rodger M. Packers, pushers and stuffersmanaging patients with concealed drugs in UK emergency departments: a clinical and medicolegal review. Emerg Med J. 2009;26:316-20. doi: 10.1136/emj.2008.057695.

3. Silverberg D, Menes T, Kim U. Surgery for "body packers"-a 15-year experience. World J Surg. 2006;30:541-6. doi: 10.1007/s00268-005-0429-7.

4. Bulstrode N, Banks F, Shrotria S. The outcome of drug smuggling by'body packers'--the British experience. Ann R Coll Surg Engl. 2002;84:35-8.

5. Deitel $M$, Syed A. Intestinal obstruction by an unusual foreign body. Can Med Assoc J. 1973;109(3):211-2.

6. Philip R, Aidayanti D. Uncommon sites for body stuffing: a literature review. British Journal of Medicine and Medical Research. 2014;4(10):1943.

7. Hergan K, Kofler K, Oser W. Drug smuggling by body packing: what radiologists should know about it. Eur Radiol. 2004;14(4):736-42. doi: 10.1007/s00330-003-2091-5 .

8. Pidoto RR, Agliata AM, Bertolini R, Mainini A, Rossi G, Giani G. A new method of packaging cocaine for international traffic and implications for the management of cocaine body packers. J Emerg Med. 2002;23(2):149-53. doi: 10.1016/ s0736-4679(02)00505-x.

9. Gill JR, Graham SM. Ten years of "body packers" in New York City: 50 deaths. J Forensic Sci. 2002;47(4): 843-6.

10. Cappelletti S, Piacentino D, Sani G, Bottoni E, Fiore PA, Aromatario $\mathrm{M}$, et al. Systematic review of the toxicological and radiological features of body packing. Int J Legal Med. 2016;130(3):693-709. doi: 10.1007/s00414-015-1310-3.

11. Krishnan A, Brown R. Plain abdominal radiography in the diagnosis of the" body packer". J Accid Emerg Med.
1999;16(5):381. doi: 10.1136/emj.16.5.381.

12. June R, Aks SE, Keys N, Wahl M. Medical outcome of cocaine bodystuffers1. J Emerg Med. 2000;18(2):221-4. doi:10.1016/ s0736-4679(99)00198-5.

13. Norfolk G. The fatal case of a cocaine body-stuffer and a literature review-towards evidence based management. J Forensic Leg Med. 2007;14(1):49-52. doi: 10.1016/j. jcfm.2005.12.002.

14. Schaper A, Hofmann R, Ebbecke M, Desel H, Langer C. Cocaine-body-packing. Infrequent indication for laparotomy [in Germany]. Chirurg. 2003;74(7):626-631. doi:10.1007/ s00104-002-0603-5

15. McCarron MM, Wood J. The cocaine 'body packer' syndrome. Diagnosis and treatment. JAMA. 1983;250(11):1417-1420.

16. de Bakker JK, Nanayakkara P, Geeraedts L, De Lange E, Mackintosh M, Bonjer H. Body packers: a plea for conservative treatment. Langenbecks Arch Surg. 2012;397(1):125-130. doi: 10.1007/s00423-011-0846-z.

17. Shahnazi M, Sanei Taheri M, Pourghorban R. Body packing and its radiologic manifestations: a review article. Iran J Radiol. 2011;8(4):205-210. doi: 10.5812/iranjradiol.4757.

18. Mandava N, Chang RS, Wang JH, Bertocchi M, Yrad J, Allamaneni $\mathrm{S}$, et al. Establishment of a definitive protocol for the diagnosis and management of body packers (drug mules). Emerg Med J. 2011;28(2):98-101. doi: 10.1136/ emj.2008.059717

19. Alipour-faz A, Shadnia S, Mirhashemi SH, Peyvandi M, Oroei $\mathrm{M}$, Shafagh $\mathrm{O}$, et al. Assessing the epidemiological data and management methods of body packers admitted to a referral center in Iran. Medicine (Baltimore). 2016;95(19):e3656. doi: 10.1097/MD.0000000000003656.

20. Wong G, Lai K, Chung C. Management of body packers in the emergency department. Hong Kong Journal of Emergency Medicine. 2005; 12(2):112-8.

21. Yang RM, Li L, Feng J, Lai SS, Lin BQ, Yu T, et al. Heroin body packing: clearly discerning drug packets using CT. South Med J. 2009;102(5):470-5. doi: 10.1097/SMJ.0b013e31819ecacc.

22. Soriano-Perez MJ, Serrano-Carrillo JL, Marin-Montin I, CruzCaballero A. Hashish body packing: a case report. Case Rep Med. 2009;2009:712573. doi: 10.1155/2009/712573.

23. Flach PM, Ross SG, Ampanozi G, Ebert L, Germerott T, Hatch GM, et al. "Drug mules" as a radiological challenge: sensitivity and specificity in identifying internal cocaine in body packers, body pushers and body stuffers by computed tomography, plain radiography and Lodox. Eur J Radiol. 2012;81(10):251826. doi: 10.1016/j.ejrad.2011.11.025.

24. Mackway-Jones K. Towards evidence based emergency medicine: best BETs from the Manchester Royal Infirmary. Emerg Med J. 2006;23(4):300. doi: 10.1136/emj.2006.035121.

25. Greenberg R, Greenberg Y, Kaplan O. 'Body Packer'Syndrome: Characteristics and Treatment-Case Report and Review. Eur J Surg. 2000;166(1):89-91. doi: $10.1080 / 110241500750009780$.

26. de Prost N, Lefebvre A, Questel F, Roche N, Pourriat J-L, Huchon G, et al. Prognosis of cocaine body-packers. Intensive Care Med. 2005;31(7):955-8. doi: 10.1007/s00134-0052660-y.

27. Peake ST, Das S, Greene S, Dubrey SW. Cocaine 'body packers' and the clinical management of packet rupture. $\mathrm{Br}$ J Hosp Med (Lond). 2009;70(2):110-111. doi: 10.12968/ hmed.2009.70.2.38914.

28. Beckley I, Ansari NA, Khwaja HA, Mohsen Y. Clinical management of cocaine body packers: the Hillingdon experience. Can J Surg. 2009;52(5):417-21.

29. Pinto A, Reginelli A, Pinto F, Sica G, Scaglione M, Berger F, et al. Radiological and practical aspects of body packing. $\mathrm{Br} J$ Radiol. 2014;87(1036):20130500. doi:10.1259/bjr.20130500 30. Hassanian-Moghaddam H, Abolmasoumi Z. Consequence of 
body packing of illicit drugs. Arch Iran Med. 2007;10(1):20-3.

31. Heymann-Maier L, Trueb L, Schmidt S, Carron PN, Hugli O, Heymann E, et al. Emergency department management of body packers and body stuffers. Swiss Med Wkly. 2017;147:w14499. doi: 10.4414/smw.2017.14499.

32. Alfa-Wali M, Atinga A, Tanham M, Iqbal Q, Meng AY, Mohsen Y. Assessment of the management outcomes of body packers. ANZ J Surg. 2016;86(10):821-5. doi: 10.1111/ans.13226.

33. Markovits N, Kurnik D, Halkin H, Guranda L, Cohen A, Katz $\mathrm{M}$, et al. "Body packers" in Israel: a case series. Isr Med Assoc J. 2013;15(10):639-645.

34. Hoffman RS, Smilkstein MJ, Goldfrank LR. Whole bowel irrigation and the cocaine body-packer: a new approach to a common problem. Am J Emerg Med. 1990;8(6):523-527. doi:10.1016/0735-6757(90)90155-s

35. Leo P, Sachter J, Melrose M. Heroin bodypacking. J Accid Emerg Med. 1995;12(1):43-8. doi: 10.1136/emj.12.1.43.

36. Gherardi R, Leporc P, Dupeyron J-P, Baud F, Marc B, Diamant-Berger O. Detection of drugs in the urine of bodypackers. Lancet. 1988;1(8594):1076-8. doi: 10.1016/s0140-
6736(88)91897-1.

37. Megarbane B, Ekherian JM, Couchard AC, Goldgran-Toledano D, Baud F. Surgery to save body-packers. Ann Fr Anesth Reanim. 2004;23(5):495-8. doi: 10.1016/j.annfar.2003.12.017.

38. Veyrie N, Servajean S, Aissat A, Corigliano N, Angelakov C, Bouillot JL. Value of a systematic operative protocol for cocaine body packers. World J Surg. 2008;32(7):1432-1437. doi: 10.1007/s00268-007-9432-5.

39. Olmedo R, Nelson L, Chu J, Hoffman RS. Is surgical decontamination definitive treatment of "body-packers"? Am J Emerg Med. 2001;19(7):593-596. doi:10.1053/ ajem.2001.21720

40. Yegane RA, Bashashati M, Hajinasrollah E, Heidari K, Salehi NA, Ahmadi M. Surgical approach to body packing. Dis Colon Rectum. 2009;52(1):97-103. doi: 10.1007/ DCR.0b013e31819738c9.

41. East JM. Surgical complications of cocaine body-packing: a survey of Jamaican hospitals. West Indian Med J. 2005;54(1):3841. doi: 10.1590/s0043-31442005000100008. 